\title{
Microbial Rhodopsins: Phylogenetic and Functional Diversity
}

John L. Spudich and Kwang-Hwan Jung

1.1

Introduction

The first 30 years of research on microbial rhodopsins concerned exclusively four proteins that share the cytoplasmic membrane of the halophilic archaeon Halobacterium salinarum, and a few very close homologs found in related haloarchaea. These four haloarchaeal types were the only microbial retinylidene proteins known prior to 1999: the light-driven ion pumps bacteriorhodopsin [BR (Oesterhelt and Stoeckenius, 1973)] and halorhodopsin [HR (Matsuno-Yagi and Mukohata, 1977; Schobert and Lanyi, 1982)], and the phototaxis receptors sensory rhodopsin I [SRI (Bogomolni and Spudich, 1982)], and sensory rhodopsin II [SRII (Takahashi et al., 1985)]. Studies of the haloarchaeal rhodopsins by the most incisive biophysical and biochemical tools available produced a wealth of information making them some of the best understood membrane-embedded proteins in terms of their structure-function relationships. Crystal structures of three [BR (Essen et al., 1998; Grigorieff et al., 1996; Luecke et al., 1999), HR (Kolbe et al., 2000), and SRII (Gordeliy et al., 2002; Kunji et al., 2001; Luecke et al., 2001; Royant et al., 2001)] reveal a common seven-transmembrane $\alpha$ helical structure with nearly identical helix positions in the membrane, despite their differing functions and identity in only $\sim 25 \%$ of their residues. The positions differ from those of visual pigments, as shown by the crystal structure of bovine rod rhodopsin (Palczewski et al., 2000), but their overall topologies are similar, namely the seven helices form an interior binding pocket in the hydrophobic core of the membrane for the retinal chromophore. In both the microbial and visual pigments, the retinal is attached by a protonated Schiff base linkage to a lysine in the middle of the seventh helix and retinal photoisomerization initiates their photochemical reactions.

Starting in 1999, genome sequencing of cultivated microorganisms began to reveal the previously unsuspected presence of archaeal rhodopsin homologs in several organisms in the other two domains of life, namely Bacteria and Eukarya (Bieszke et al., 1999a; Jung et al., 2003; Sineshchekov et al., 2002). Further, in 2001, "environmental genomics" of populations of uncultivated microorganisms in ocean plankton 
showed the presence of a homolog in marine proteobacteria [hence given the name proteorhodopsin (Beja et al., 2000)], which has swiftly expanded so far to $\sim 800$ relatives identified in samples throughout the world's oceans (Beja et al., 2001; de la Torre et al., 2003; Man et al., 2003; Man-Aharonovich et al., 2004; Sabehi et al., 2003; Venter et al., 2004). Microorganisms containing rhodopsin genes inhabit diverse environments including salt flats, soil, fresh water, surface and deep sea water, glacial sea habitats, and human and plant tissues as fungal pathogens. They comprise a broad phylogenetic range of microbial life, including haloarchaea, proteobacteria, cyanobacteria, fungi, dinoflagellates, and green algae. The conservation of residues, especially in the retinal-binding pocket, define a large phylogenetic class, called type 1 rhodopsins to distinguish them from the visual pigments and related retinylidene proteins in higher organisms (type 2 rhodopsins).

Analysis of the sequences of the new type 1 rhodopsins, their heterologous expression and study, and in some cases study of the photosensory physiology of the organisms containing them, and spectroscopic analysis of environmental samples, have shown that the newfound pigments fulfill both ion-transport and sensory functions, the latter with a variety of signal-transduction mechanisms. The purpose of this chapter is to summarize what we have learned regarding the rapidly expanding group of retinylidene pigments comprising the microbial rhodopsin family.

\section{2}

\section{Archaeal Rhodopsins}

Many laboratories have characterized the four rhodopsins from $H$. salinarum with a battery of techniques because they provide model systems for the two fundamental functions of membranes: active transport and sensory signaling. Comprehensive reviews on mechanisms of BR (Lanyi and Luecke, 2001), HR (Varo, 2000), and the SRs (Hoff et al., 1997; Spudich et al., 2000) are available. Sixteen variants of BR, HR, SRI and SRII have been documented in related halophilic archaea, such as Natronomonas pharaonis and Haloarcula vallismortis (Table 1.1).

Identification of members of the type- 1 family has been based primarily on the conservation of residues in the retinal-binding pocket, which is known from the structures of haloarchaeal members. Atomic resolution structures, which exist for only a small number of membrane proteins, have been obtained from electron microscopy and X-ray crystallography of three of the archaeal rhodopsins: BR and HR from $H$. salinarum, and SRII from $N$. pharaonis ("NpSRII"). These proteins share a nearly identical positioning of seven transmembrane helices forming an interior pocket for the chromophore, all-trans retinal. The retinal binding pocket is comprised of residues from each of the seven helices, and it is the conservation of these residues that provides the most definitive identification of archaeal rhodopsin homologs in other organisms. Conservation outside of the pocket is sparse (Figure 1.1). Even between members of the archaeal branch, conservation outside the pocket is limited. For example, the phototaxis receptor NpSRII is only $27 \%$ identical to BR in amino acid sequence, and exhibits typically $\sim 40 \%$ identity with other archaeal sensory 
Table 1.1 List of microbial rhodopsins with database accession numbers or other sources. We show all microbial opsin genes found in the NCBI database except proteorhodopsins, for which $\sim 800$ have been identified (see text). We selectively present a subset of proteorhodopsins for which absorption maxima have been published. BR, bacteriorhodopsin; HR, halorhodopsin; SRI \& SRII, sensory rhodopsins I and II; PR, proteorhodopsin; NOPI, Neurospora opsin I; CSRA \& CSRB, Chlamydomonas sensory rhodopsins A and B.

\begin{tabular}{ll}
\hline Species and Name & $\begin{array}{l}\text { Accession } \\
\text { Number }\end{array}$ \\
\hline
\end{tabular}

\begin{tabular}{|c|c|c|}
\hline \multicolumn{3}{|l|}{ Archaea } \\
\hline Haloarcula argentinensis BR & D31880 & $\mathrm{H}^{+}$pump \\
\hline Haloarcula japonica BR & AB029320 & $\mathrm{H}^{+}$pump \\
\hline Haloarcula sp. (Andes) BR & S76743 & $\mathrm{H}^{+}$pump \\
\hline Haloarcula vallismortis BR & D31882 & $\mathrm{H}^{+}$pump \\
\hline Haloarcula vallismortis $\mathrm{HR}$ & D31881 & $\mathrm{Cl}^{-}$pump \\
\hline Haloarcula vallismortis SRI & D83748 & phototaxis \\
\hline Haloarcula vallismortis SRII & Z35308 & phototaxis \\
\hline Halobacterium marismotui BR & - & $\begin{array}{l}\mathrm{H}^{+} \text {pump by homology with BR, } \\
\text { Victor Ng, pers. com. }\end{array}$ \\
\hline Halobacterium marismotui HR & - & $\begin{array}{l}\mathrm{Cl}^{-} \text {pump by homology with } \mathrm{HR} \text {, } \\
\text { Victor } \mathrm{Ng} \text {, pers. com. }\end{array}$ \\
\hline Halobacterium marismotui SRI & - & phototaxis, Victor Ng, pers. com. \\
\hline Halobacterium marismotui SRII & - & phototaxis, Victor Ng, pers. com. \\
\hline Halobacterium marismotui BR-2 & - & unknown,Victor Ng, pers. com. \\
\hline Halobacterium marismotui SRI-2 & - & unknown,Victor Ng, pers. com. \\
\hline Halobacterium salinarum BR & V00474 & $\begin{array}{l}\lambda_{\max }=568 \mathrm{~nm} \\
\mathrm{H}^{+} \text {pump }\end{array}$ \\
\hline Halobacterium salinarum HR & D43765 & $\begin{array}{l}\lambda_{\max }=576 \mathrm{~nm} \\
\mathrm{Cl}^{-} \text {pump }\end{array}$ \\
\hline Halobacterium salinarum SRI & L05603 & $\begin{array}{l}\lambda_{\max }=587 \mathrm{~nm}, \\
\text { phototaxis (attractant/repellent) }\end{array}$ \\
\hline Halobacterium salinarum SRII & U62676 & $\begin{array}{l}\lambda_{\max }=487 \mathrm{~nm}, \\
\text { phototaxis (repellent) }\end{array}$ \\
\hline Halobacterium salinarum mex BR & D11056 & $\mathrm{H}^{+}$pump \\
\hline Halobacterium salinarum mex HR & P33970 & $\mathrm{Cl}^{-}$pump \\
\hline Halobacterium salinarum port BR & D11057 & $\mathrm{H}^{+}$pump \\
\hline Halobacterium salinarum port HR & Q48315 & $\mathrm{Cl}^{-}$pump \\
\hline Halobacterium salinarum shark BR & D11058 & $\mathrm{H}^{+}$pump \\
\hline Halobacterium salinarum shark HR & D43765 & $\mathrm{Cl}^{-}$pump \\
\hline Halobacterium sp. AUS-1 BR & J05165 & $\mathrm{H}^{+}$pump \\
\hline Halobacterium sp. AUS-1 SRII & AB059748 & phototaxis \\
\hline Halobacterium sp. AUS-2 BR & S56354 & $\mathrm{H}^{+}$pump \\
\hline Halobacterium sp. NRC-1 BR & NP_280292 & $\mathrm{H}^{+}$pump \\
\hline Halobacterium sp. NRC-1 HR & NP_279315 & $\mathrm{Cl}^{-}$pump \\
\hline Halobacterium sp. NRC-1 SRI & AAG19914 & $\begin{array}{l}\lambda_{\max }=587 \mathrm{~nm}, \\
\text { phototaxis (attractant/repellent) }\end{array}$ \\
\hline Halobacterium sp. NRC-1 SRII & AAG19988 & $\begin{array}{l}\lambda_{\max }=487 \mathrm{~nm}, \\
\text { phototaxis (repellent) }\end{array}$ \\
\hline Halobacterium sp. SG1 BR & X70291 & $\mathrm{H}^{+}$pump \\
\hline Halobacterium sp. SG1 HR & X70292 & $\mathrm{Cl}^{-}$pump \\
\hline
\end{tabular}


Table 1.1 Continued

\begin{tabular}{|c|c|c|}
\hline Species and Name & $\begin{array}{l}\text { Accession } \\
\text { Number }\end{array}$ & Comments \\
\hline \multicolumn{3}{|l|}{ Archaea } \\
\hline Halobacterium sp. SG1 SRI & X70290 & phototaxis \\
\hline Halorubrum sodomense BR & D50848 & $\mathrm{H}^{+}$pump \\
\hline Halorubrum sodomense HR & AB009622 & $\mathrm{Cl}^{-}$pump \\
\hline Halorubrum sodomense SRI & AB009623 & phototaxis \\
\hline Haloterrigena sp. Arg-4 BR & AB009620 & $\mathrm{H}^{+}$pump \\
\hline Haloterrigena sp. Arg-4 HR & AB009621 & $\mathrm{Cl}^{-}$pump \\
\hline Natronomonas pharaonis HR & J05199 & $\mathrm{Cl}^{-}$pump \\
\hline Natronomonas pharaonis SRII & Z35086 & $\begin{array}{l}\lambda_{\max }=497 \mathrm{~nm}, \\
\text { phototaxis (repellent) }\end{array}$ \\
\hline \multicolumn{3}{|l|}{ Eubacteria } \\
\hline Anabaena sp. PCC7120 & AP003592 & $\begin{array}{l}\text { Also known as Nostoc, } \lambda_{\max } 543 \mathrm{~nm} \text {, } \\
\text { photosensory }\end{array}$ \\
\hline Gloeobacter violaceus PCC 7421 & NP_923144 & Unicellular cyanobacterium \\
\hline Magnetospirillum magnetotacticum & - & genome.ornl.gov/microbial/mmag \\
\hline$\gamma$-proteobacterium (BAC31A8) & AF279106 & $\begin{array}{l}\lambda_{\max }=527 \mathrm{~nm} \\
\mathrm{H}^{+} \text {pump; GPR }\end{array}$ \\
\hline$\gamma$-proteobacterium (HOT75m4) & AF349981 & $\lambda_{\max }=490 \mathrm{~nm}, \mathrm{H}^{+}$pump; BPR \\
\hline$\gamma$-proteobacterium (HOT0m1) & AF349978 & $\lambda_{\max }=518 \mathrm{~nm}$ \\
\hline$\gamma$-proteobacterium (PalE6) & AAK30200 & $\lambda_{\max }=490 \mathrm{~nm}$ \\
\hline$\gamma$-proteobacterium (eBac64A5) & AAK30175 & $\lambda_{\max }=519 \mathrm{~nm}$ \\
\hline$\gamma$-proteobacterium (eBac40E8) & AAK30174 & $\lambda_{\max }=519 \mathrm{~nm}$ \\
\hline$\gamma$-proteobacterium (RSr6a5a6) & AAO21455 & $\lambda_{\max }=540 \mathrm{~nm}$ \\
\hline$\gamma$-proteobacterium (RS23) & AAO21449 & $\lambda_{\max }=528 \mathrm{~nm}$ \\
\hline$\gamma$-proteobacterium (RSr6a5a2) & - & $\begin{array}{l}\lambda_{\max }=505 \mathrm{~nm}, \\
\text { RSr6a5a6(V105E), from Oded Béjà }\end{array}$ \\
\hline \multicolumn{3}{|l|}{ Fungi } \\
\hline Botrytis cinerea & AL115930 & \\
\hline Botryotinia fuckeliana & - & cogeme.ex.ac.uk \\
\hline Cryptococcus neoformans & CF192410 & $\begin{array}{l}\text { www.genome.ou.edu/cneo.html, } \\
\text { Basidiomycetes }\end{array}$ \\
\hline Fusarium sporotrichioides & BI187800 & \\
\hline Fusarium graminearum & BU067691 & \\
\hline Leptosphaeria maculans & AF290180 & \\
\hline Mycosphaerella graminicola & AW180117 & two homologs are present \\
\hline Neurospora crassa NR & AF135863 & $\lambda_{\max }=534 \mathrm{~nm}$ \\
\hline Triticum aestivum & CA747087 & \\
\hline Ustilago maydis & CF642219 & Basidiomycetes \\
\hline \multicolumn{3}{|l|}{ Algae } \\
\hline Chlamydomonas reinhardtii CSRA & AF508965 & photomotility for high light intensity \\
\hline Chlamydomonas reinhardtii CSRB & AF508966 & photomotility for low light intensity \\
\hline Pyrocystis lunula & AF508258 & dinoflagellate \\
\hline Guillardia theta & AW342219 & cryptomonad \\
\hline Acetabularia acetabulum & CF259014 & green alga \\
\hline
\end{tabular}


rhodopsins; all 4 archaeal rhodopsins exhibit $\sim 80 \%$ identity in the 22 residues that the crystal structures show form the retinal binding pockets in BR, HR, and NpSRII. 55$75 \%$ identity in these 22 residues is also found in the new rhodopsins (Figure 1.1).

The functions of the four archaeal rhodopsins have been well characterized. BR $\left(\lambda_{\max }=568 \mathrm{~nm}\right)$ and HR $\left(\lambda_{\max }=576 \mathrm{~nm}\right)$ are light-driven ion pumps for protons and chloride, respectively, absorbing maximally in the green-orange region of the spectrum (Oesterhelt, 1998; Varo, 2000). Their electrogenic transport cycles provide energy to the cell under conditions in which respiratory electron transport activity is low. Accordingly, their production in the cells is induced when oxygen is depleted in late exponential/early stationary phase cultures. Both BR and HR hyperpolarize the membrane to generate a positive outside membrane potential, thereby creating inwardly directed proton motive force. HR further contributes to $\mathrm{pH}$ homeostasis by hyperpolarizing the membrane by electrogenic chloride uptake rather than proton ejection, thereby providing an electrical potential for net proton uptake especially important in alkaline conditions.

SRI and SRII are phototaxis receptors controlling the cell's swimming behavior in response to changes in light intensity and color (Hoff et al., 1997). SRI $\left(\lambda_{\max }=587 \mathrm{~nm}\right)$ is also induced in cells in late exponential/early stationary phase, and attracts the cells to orange light useful to the transport rhodopsins. SRI is unique among known photosensory receptors in that it produces opposite signals (attractant and repellent) depending on the wavelengths of stimulating light. To avoid guiding the cells into light containing harmful near-UV radiation, SRI uses its color-discriminating mechanism to ensure the cells will be attracted to orange light only if that light is not accompanied by near-UV wavelengths (Spudich and Bogomolni, 1984). The mechanism is based on photochromic reactions of the protein. If SRI absorbs a single photon (maximal absorption in the orange) it produces a photointermediate species called SRI-M or $\mathrm{S}_{373}\left(\lambda_{\max }=373 \mathrm{~nm}\right)$ that is interpreted by the cells' signal transduction machinery as an attractant signal. However, if $S_{373}$ is photoexcited, it generates a strongly repellent-signaling photointermediate. Therefore single-photon excitation of SRI, such as occurs in orange light, attracts the cells, whereas two-photon excitation, as occurs in white light, repels the cells. SRII absorbs in the mid-visible range $\left(\lambda_{\max }=487 \mathrm{~nm}\right.$ in $H$. salinarum SRII) and appears to serve only a repellent function (Takahashi et al., 1990). It is the only rhodopsin in H. salinarum produced in cells during vigorous aerobic grow when light is not being used for energy and is therefore best avoided because of possible photooxidative damage. 


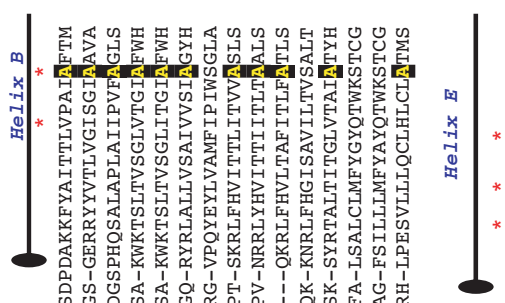

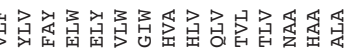

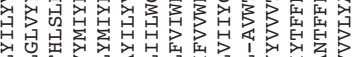

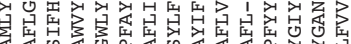

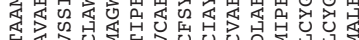
由心



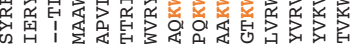

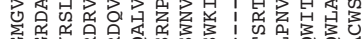

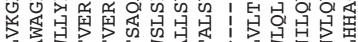

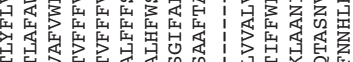

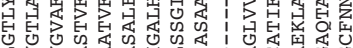

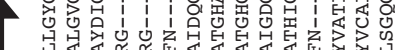

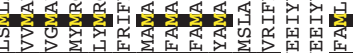

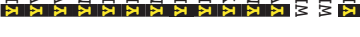
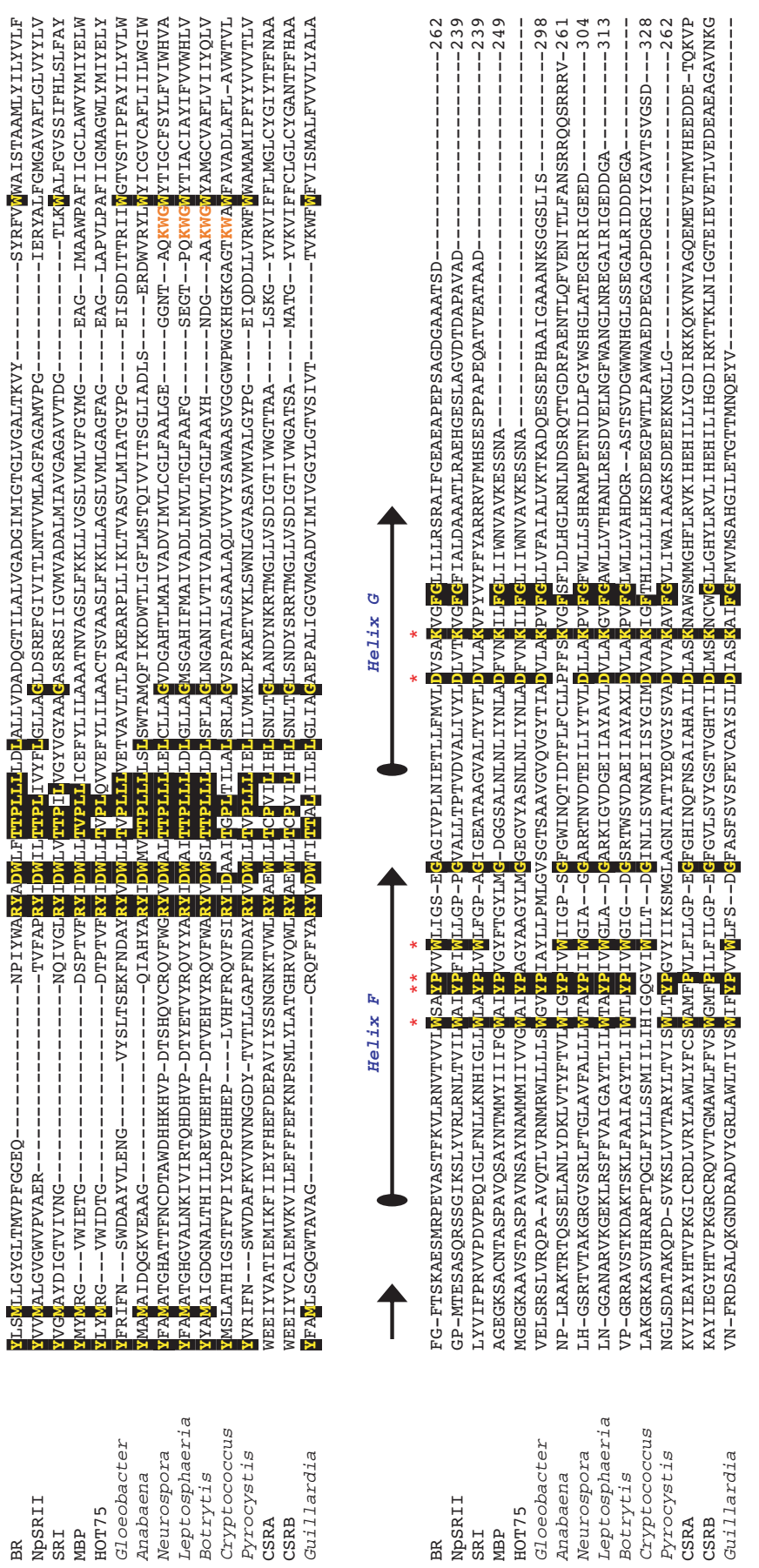

\section{政}


1.3

\section{Clues to Newfound Microbial Rhodopsin Function from Primary Sequence Comparison to Archaeal Rhodopsins}

A challenge posed by the newfound microbial rhodopsin genes is to identify the photochemical and physiological function of the proteins in the cells containing them, some of which are uncultivated microorganisms. Success has been obtained in several cases: as detailed below, the Monterey Bay surface water-proteorhodopsin functions as a light-driven proton pump for the $\gamma$-proteobacterium SAR86 in its native marine environment (Beja et al., 2001; de la Torre et al., 2003), and therefore its physiological function is similar to that of BR in H. salinarum. In contrast, the Anabaena (Nostoc) rhodopsin (Jung et al., 2003) and Chlamydomonas reinhardtii pigments CSRA and CSRB (Sineshchekov et al., 2002) have been demonstrated to serve photosensory rather than transport functions, and therefore are functionally more similar to the archaeal SRI and SRII. These known transport proteins and sensory proteins do not group separately in phylogenetic analyses (Figure 1.2); therefore the phylogenetic trees do not permit assignment of particular sequences as encoding transport or sensory proteins. Some individual residue differences, however, provide a clue, as do the photochemical reaction cycle kinetics of the proteins.

One difference in the primary sequence between BR, HR and the SRs stands out. Asp96 in BR functions as a proton donor, returning a proton to the Schiff base from the cytoplasmic side of the protein during the pumping cycle. This proton transfer improves the pumping efficiency of BR by accelerating the decay of its unprotonated Schiff base photocycle intermediate, $\mathrm{M}$, and is present in all BR homologs in the haloarchaea. In the sensory rhodopsins, the corresponding $\mathrm{M}$ intermediates are signaling states of the receptor proteins (demonstrated unequivocally only for HsSRI), and longer $\mathrm{M}$ lifetimes increase the signaling efficiencies of the receptors. Accordingly, each of the five known haloarchaeal sensory rhodopsin sequences lacks a carboxylate residue at the position corresponding to Asp96 and contains Tyr or Phe instead. The residue corresponding to Asp85, which is the proton acceptor from the Schiff base, is a carboxylate residue in BR, SRI, and SRII and in each of the newly

4 Figure 1.1 Primary sequence comparison of 15 microbial rhodopsins. We selected several opsin genes from each domain of life.

Archaea- BR: Halobacterium salinarum bacteriorhodopsin, SRI: H. salinarum sensory rhodopsin I, NpSRII: Natronomonas pharaonis sensory rhodopsin II; Bacteria- GPR: $\gamma$-proteobacterium (BAC31A8) proteorhodopsin, BPR: $\gamma$-proteobacterium (HOT75m4) proteorhodopsin, Gloeobacter: microbial rhodopsin from Gloeobacter violaceus PCC 7421, Anabaena: sensory rhodopsin from Anabaena (Nostoc) sp. PCC7120; Eukarya- Fungirhodopsin from Neurospora crassa, Leptosphaeria maculans, Botrytis cinerea, and Cryp- tococcus neoformans, Algae- Pyrocyctis: rhodopsin from Pyrocystis lunula, CSRA \& CSRB: Chlamydomonas reinhardtii sensory rhodopsins $\mathrm{A}$ and $\mathrm{B}$ ( $\mathrm{N}$-terminal portions), Guillardia: rhodopsin from Guillardia theta. Conserved residues are marked with black background and the 22 residues in the retinalbinding pocket are marked with asterisks. Bacteriorhodopsin Asp85 and Asp96 in helix C and corresponding residues in the other pigments are marked with blue background (see text). Red-colored KWG residues on helix $E$ are nearly completely conserved in fungal rhodopsins. 





Figure 1.2 Phylogenetic tree of microbial rhodopsins. A neighbor-joining tree was constructed from CLUSTALX(1.81) alignment of 46 microbial rhodopsin apoproteins. The tree was constructed using the full-length sequences, except in the case of Chlamydomonas sensory opsins, in which only the rhodopsin domains were used (CsoA, $378 \mathrm{~N}$-terminal residues; $\mathrm{CsoB}, 303 \mathrm{~N}$-terminal residues). Scale represents number of substitutions per site $(0.1$ indicates 10 nucleotide substitutions per 100 nucleotides). 1000 bootstrap replicates were performed to determine the reliability of the tree topology. The tree was drawn using TreeView1.6.6. Abbreviations: NOPI (Neurospora crassa opsin I), HtHR (Haloterrigena sp. halorhodopsin), HvalHR (Haloarcula vallismortis halorhodopsin), HsHR (Halobacterium salinarum halorhodopsin), HsportHR (Halobacterium salinarum port halorhodopsin), NpHR (Natronomonas pharaonis halorhodopsin), HsodHR (Halorubrum sodomense halorhodopsin), HspSGIHR (Halobacterium sp. SG1 halorhodopsin), AnabaenaSR (Anabaena (Nostoc) sp. PCC7120 sensory rhodopsin), HtBR (Haloterrigena sp. bacteriorhodopsin), HaspBR (Haloarcula sp. bacteriorhodopsin), HvalBR (Haloarcula vallismortis bacteriorhodopsin), HajaponicaBR (Haloarcula japonica bacteriorhodopsin), HaargentBR (Haloarcula argentinensis bacteriorhodopsin), HsportBR (Halobacterium salinarum port bacteriorhodopsin), HsBR (Halobacterium salinarum bacteriorhodopsin), HsmexBR (Halobacterium salinarum mex bacteriorhodopsin), HspAUS-2BR (Halobacterium sp. AUS-2 bacteriorhodopsin), HsodBR (Halorubrum sodomense bacteriorhodopsin), HspAUS-1BR (Halobacterium sp. AUS-1 bacteriorhodopsin), HvalSRII (Haloarcula vallismortis sensory rhodopsin II), NpSRII (Natronomonas pharaonis sensory rhodopsin II), HspAUS-1SRII (Halobacterium sp. AUS-1 sensory rhodopsin II), HsSRII (Halobacterium salinarum sensory rhodopsin II), HsodSRI (Halorubrum sodomense sensory rhodopsin I), HvalSRI (Haloarcula vallismortis sensory rhodopsin I), HsSRI (Halobacterium salinarum sensory rhodopsin I), PR eBAC64A5 ( $\gamma$-proteobacterium proteorhodopsin), PR MBP (GPR; $\gamma$-proteobacterium proteorhodopsin BAC21A8), CSRA and CSRB (Chlamydomonas reinhardtii sensory rhodopsins $A$ and $B$, respectively).

identified rhodopsins (Figure 1.1). HR does not produced an unprotonated Schiff base intermediate in its photocycle, and therefore does not contain a carboxylic acid residue in either of the positions corresponding to Asp96 and Asp85.

Notably the SAR86 proteorhodopsin demonstrated to be a light-driven proton pump does contain a carboxylate (Glu108) at the position corresponding to Asp96 in BR, and moreover Glu108 has been shown to participate in the reprotonation of the Schiff base in the latter half of the photocycle as does Asp96 in BR (Dioumaev et al., 2002; Wang et al, 2003). On the basis of available information, the presence of the carboxylate residue at this position appears to be a necessary, but not a sufficient condition for identification of a new rhodopsin as a proton pump. Neurospora rhodopsin also contains a glutamate at this position, but extensive analysis of the photoactivity of the protein expressed in Pichia pastoris, as well as purified and reconstituted into liposomes, reveals a non-transport photocycle with kinetics indicative of a sensory rhodopsin (Bieszke et al., 1999b). A caveat is that one cannot be certain that the protein is folded correctly when expressed heterologously, although the absorption spectrum in the visible range and photochemical reactivity of the expressed protein when reconstituted with all-trans retinal provides some assurance.

The demonstrated sensory rhodopsins, namely the archaeal SRI and SRII proteins, the Anabaena rhodopsin, and Chlamydomonas CSRA and CSRB, all lack a carboxylate residue at the homologous position of the BR Schiff base proton donor Asp96, while containing the carboxylate Schiff base proton-acceptor residue corresponding to 
Asp85 in BR (Figure 1.1). Hence the absence of a carboxylate in the donor position in Cryptococcus neoformans (alanine in the corresponding position) and in a marine proteorhodopsin sequence recently deposited in GenBank (gi|42850614|gb|EAA92632.1, threonine in the corresponding position) strongly suggest sensory functions for these proteins.

More than 10-fold faster photocycling rates distinguish the archaeal transport from the sensory pigments; the first-found sensory rhodopsin, archaeal SRI, in fact was initially called "slow-cycling rhodopsin" for this reason (Bogomolni and Spudich, 1982; Spudich et al., 1995). The transport rhodopsins are characterized by photocycles typically $<30 \mathrm{~ms}$, whereas sensory rhodopsins are slow-cycling pigments with photocycle halftimes typically $>300 \mathrm{~ms}$ (Spudich et al., 2000). This large kinetic difference is functionally important since a rapid photocycling rate is advantageous for efficient ion pumping, whereas a slower cycle provides more efficient light detection because signaling states persist for longer times.

The photocycle rate difference, which holds firm for the archaeal rhodopsins, may in some cases not be a definitive criterion for assigning a transport versus sensory function. The Anabaena rhodopsin which has been concluded to be a sensory protein based on other criteria has a photocycle half-time of $110 \mathrm{~ms}$ (Jung et al., 2003), intermediate between archaeal transport and sensory proteins. Furthermore, a deep sea proteorhodopsin from a Hawaiian Ocean-Time station plankton sample from $75 \mathrm{~m}$ depth exhibits a light-driven proton transport cycle that is $\sim 10$-fold slower (60 $\mathrm{ms}$ in cells) than that of the Monterey Bay proteorhodopsin (Wang et al., 2003). The slower photocycling rate of the deep sea pigment is explained as an adaptation to the $\sim 10$ fold decreased photon flux rate available to the BPR visible absorption band at $75 \mathrm{~m}$.

\section{4}

\section{Bacterial Rhodopsins}

\subsection{1}

\section{Green-absorbing Proteorhodopsin ("GPR") from Monterey Bay Surface Plankton}

Among the most abundant and widely distributed of the type 1 rhodopsins are the proteorhodopsins, the first of which was identified by genomic analysis of marine proteobacteria in plankton from Pacific coastal surface waters. The proteorhodopsin gene was the first found to encode a eubacterial homolog of the archaeal rhodopsins and was revealed by BAC library construction and sequencing of naturally occurring marine bacterioplankton from Monterey Bay (Beja et al., 2000). The gene was functionally expressed in Escherichia coli and bound retinal to form an active, light-driven proton pump. The rRNA sequence on the same DNA fragment identified the organism as an uncultivated $\gamma$-proteobacterium (the SAR86 group), and the expressed protein was named proteorhodopsin. Phylogenetic comparison with archaeal rhodopsins placed proteorhodopsin on an independent long branch (Figure 1.2). The new pigment, designated GPR $\left(\lambda_{\max }=525 \mathrm{~nm}\right)$, exhibited a photochemical reaction cycle with intermediates and kinetics characteristic of archaeal proton-pumping 
rhodopsins. Its transport, spectroscopic, and photochemical reactions have now been characterized by a number of laboratories in Escherichia coli-expressed forms (Beja et al., 2000; Beja et al., 2001; Dioumaev et al., 2002; Dioumaev et al., 2003; Friedrich et al., 2002; Krebs et al., 2002; Lakatos et al., 2003; Man et al., 2003). The efficient proton pumping and rapid photocycle ( $15 \mathrm{~ms}$ halftime) of the new pigment strongly suggested that proteorhodopsin functions as a proton pump in its natural environment. Asp97 and Glu108 in GPR function as Schiff base proton acceptor and donor carboxylate residues during the GPR pumping cycle, analogous to Asp85 and Asp96, respectively, at the corresponding positions in BR (Dioumaev et al., 2002; Wang et al., 2003).

The next step was examination of the plankton samples directly for the newfound protein's activity. Retinylidene pigmentation with photocycle characteristics identical to that of the E. coli-expressed proteorhodopsin gene was demonstrated by flash spectroscopy in membranes prepared from Monterey Bay picoplankton (Beja et al., 2001). Estimated from laser flash-induced absorbance changes, a high density of proteorhodopsin in the SAR86 membrane is indicated, arguing for a significant role of the protein in the physiology of these bacteria. The flash photolysis results provided direct physical evidence for the existence of proteorhodopsin-like pigments and endogenous retinal molecules in the prokaryotic fraction of the Monterey Bay coastal surface waters, and provide compelling evidence that GPR functions as a light-driven proton pump photoenergizing SAR86 cells in their natural environment. Furthermore, the amplitude of the flash-photolysis signals permit a rough estimate of the total rate of solar energy conversion to proton motive force by marine proteorhodopsins; assuming for the calculation that the Monterey Bay sample has the average PR content, the conversion rate is on the order of $10^{13}-10^{14} \mathrm{~W}$, a globally significant contribution to the biosphere.

Since the initial finding of GPR, a wide variety of similar genes has been identified in picoplankton from very different ocean environments: the Antarctic, Central North Pacific, Mediterranean Sea, Red Sea, and the Atlantic Ocean (Beja et al., 2001; de la Torre et al., 2003; Man et al., 2003; Man-Aharonovich et al., 2004; Sabehi et al., 2003). Genes have been isolated from both surface and deep-water samples, and both coastal and open-sea areas. New members from the PR family were recently reported to be found also in marine $\alpha$-proteobacteria (de la Torre et al., 2003), and based on whole genome "shotgun sequencing" of microbial populations collected en mass on tangential flow and impact filters from sea water samples collected from the Sargasso Sea near Bermuda, a remarkable 782 different partial sequences homologous to proteorhodopsins were identified (Venter et al., 2004). Thus, microbial rhodopsin abundance and diversity within marine environments appears to be large. 


\section{4 .2}

\section{Blue-absorbing Proteorhodopsin ("BPR”) from Hawaiian Deep Sea Plankton}

One of the variant groups (designated clade II) of proteorhodopsin genes, differing by $\sim 22 \%$ in predicted primary structure from the clade I group defined by the GPR gene and its close relatives, was detected in both the Antarctic and in 75-m deep ocean plankton from Hawaiian waters (Beja et al., 2001). The Antarctic and Hawaiian PR genes when expressed in $E$. coli exhibit a blue-shifted absorption spectrum $\left(\lambda_{\max }=490 \mathrm{~nm}\right.$; hence referred to as "BPR") with vibrational fine structure, unlike the unstructured spectrum of GPR (Beja et al., 2001). The stratification of the surface GPR and 75-m BPR with depth is in accordance with light spectral quality at these depths (Beja et al., 2001).

The different absorption spectra of GPR and BPR have provided an opportunity to examine "spectral tuning" in two rhodopsins with closely similar primary sequence. One of the most notable distinguishing properties of retinal among the various chromophores used in photosensory receptors is the large variation of its absorption spectrum depending on interaction with the apoprotein ("spectral tuning") (Birge, 1990; Ottolenghi and Sheves, 1989). In rhodopsins, retinal is covalently attached to the $\varepsilon$ amino group of a lysine residue forming a protonated retinylidene Schiff base. In methanol a protonated retinylidene Schiff base exhibits a $\lambda_{\max }=$ of $440 \mathrm{~nm}$. The protein microenvironment shifts the $\lambda_{\max }$ [the "opsin shift" (Yan et al., 1995)] to longer wavelengths, e.g. to $527 \mathrm{~nm}$ in GPR and to $490 \mathrm{~nm}$ in BPR. With structural modelling comparisons and mutagenesis, a single residue difference in the retinal binding pockets at position 105 (Leu in GPR and Gln in BPR) was found to function as a spectral tuning switch and to account for most of the spectral difference between the two pigment families (Man et al., 2003). The mutations at position 105 almost completely interconverted the absorption spectra of BPR and GPR. GPR L105Q shifted to the blue and acquired vibrational fine structure like wild-type BPR, and BPR Q105L shifted to the red and lost the fine structure exhibiting spectra similar to those of GPR. Among both type 1 and type 2 rhodopsins the mechanisms of spectral tuning in general are still not well understood in physical chemical terms and the Q/L switch stands out as a simple spectral tuning model amenable to investigation. Spectral tuning is discussed in more detail in Section 1.6, below.

Another difference between GPR and BPR is their photocycle halftimes, $6.5 \mathrm{~ms}$ and $60 \mathrm{~ms}$ respectively in E. coli cells (Wang et al., 2003). The difference in photocycle rates and their different absorption maxima may be explained as an adaptation to the different light intensities in their respective marine environments, based on measured spectral distributions of intensities of solar illumination at the ocean surface and at various depths (Jerlov, 1976). Taking into account the blue shift of BPR, matching the lower photon fluence rate from solar radiation requires a 10 -fold slower photocycle in BPR than in GPR. Therefore there is no selective pressure for a photocycle faster than that of BPR at that depth.

BPR may function to energize cells by light-driven electrogenic proton pumping, as does GPR. However, the contribution of solar energy capture from BPR is severely limited by the low light intensities in deep waters. This consideration raises the 
possibility of a regulatory rather than energy harvesting function of BPR, based either on its slow proton pumping or by yet unidentified protein-protein interaction with transducers in its native membrane.

\section{4 .3}

\section{Anabaena Sensory Rhodopsin}

A rhodopsin pigment in a cyanobacterium established that sensory rhodopsins also exist in eubacteria. A gene encoding a homolog of the archaeal rhodopsins was found via a genome-sequencing project of Anabaena (Nostoc) sp. PCC7120 at Kazusa Institute (http://www.kazusa.or.jp/). The opsin gene was expressed in E. coli, and bound all-trans retinal to form a pink pigment $\left(\lambda_{\max }=543 \mathrm{~nm}\right)$ with a photochemical reaction cycle containing an M-like photointermediate and $110 \mathrm{~ms}$ half-life at pH 6.8 (Jung et al., 2003).

The opsin gene was found in the genome to be adjacent to another open reading frame separated by 16 base pairs under the same promoter. This operon is predicted to encode a 261-residue protein (the opsin) and a 125 -residue $(14 \mathrm{kDa})$ protein. The rate of the photocycle is increased $\sim 20 \%$ when the Anabaena rhodopsin and the soluble protein are co-expressed in E. coli (Jung et al., 2003), indicating physical interaction between the two proteins. Binding of the $14-\mathrm{kD}$ a protein to Anabaena rhodopsin was confirmed by affinity-enrichment measurements and Biacore interaction analysis. The pigment did not exhibit detectable proton transport activity when expressed in E. coli, and Asp96, the proton donor of BR, is replaced with Ser86 in Anabaena rhodopsin. These observations are compelling that Anabaena opsin functions as a photosensory receptor in its natural environment, and strongly suggest that the 125 residue cytoplasmic soluble protein transduces a signal from the receptor, unlike the archaeal sensory rhodopsins which transmit signals by transmembrane helix-helix interactions with integral membrane transducers (Figure 1.3).

Chimeric constructs have established that the archaeal sensory rhodopsins SRI and SRII transmit signals to their cognate membrane-embedded taxis transducers by interaction with the transducers, transmembrane helices and a short membrane proximal domain (Jung et al., 2001; Zhang et al., 1999) and an extensive membraneembedded transducer-binding region has been observed in the X-ray structure of $N$. pharaonis SRII (Luecke et al., 2001) co-crystallized with its taxis transducer fragment (Gordeliy et al., 2002; see also Spudich 2002). The interaction of the soluble 14-kDa protein, likely to be a signal transducer, with Anabaena rhodopsin, therefore would extend the range of signal transduction mechanisms used by microbial sensory rhodopsins.

Atomic resolution structures for the Anabaena pigment and its putative transducer have been obtained (Vogeley et al., 2004), but the physiological function of Anabaena SR has not been established. Several photophysiological responses of Anabaena with unidentified photosensory receptor(s) have been discussed (Jung et al., 2003; Mullineaux, 2001). One of these is light-modulation of the pigments contained in the light-harvesting complex of Anabaena, a photoresponse called chromatic adaptation. Green light such as absorbed by Anabaena rhodopsin has been found to modulate 


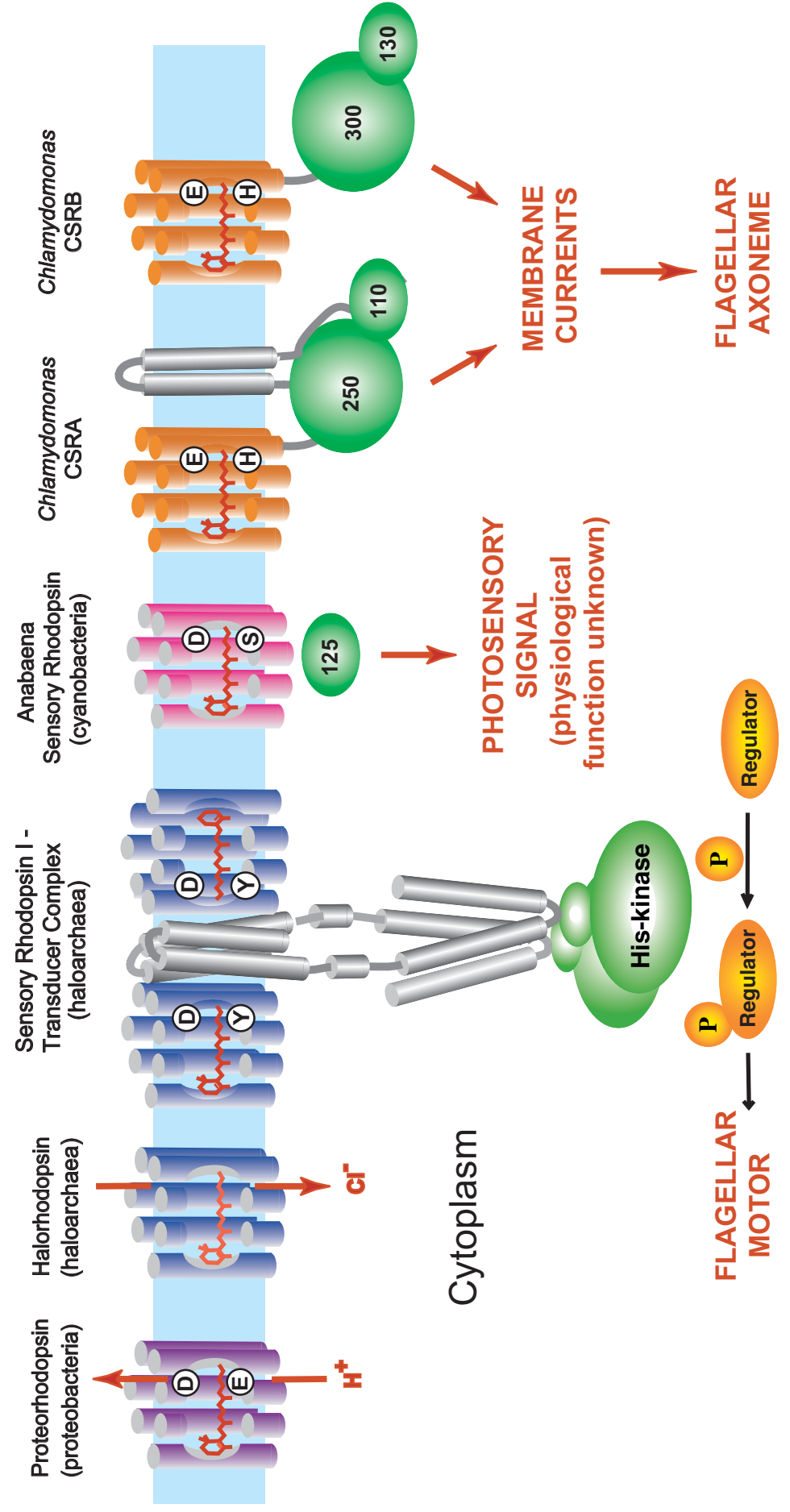


complementary chromatic adaptation in the related cyanobacteria Calothrix and Fremyella (Grossman et al., 2001). The adaptation consists of differential biosynthesis of blue-absorbing phycoerythrins and red-absorbing phycocyanins depending on light quality. The genome of Anabaena sp. 7120 contains phycoerythrin subunits $\alpha$ and $\beta$ (pecA and $B$ ), allophycocyanin subunits $\alpha$ and $\beta$ (apcA and $B$ ), and phycocyanin subunits $\alpha$ and $\beta$ (cpcA and $B$ ). Green light (optimally $540 \mathrm{~nm}$ ) promotes phycoerythrin synthesis whereas red light (optimally $650 \mathrm{~nm}$ ) promotes phycocyanin synthesis (Kehoe and Grossman, 1994). A phytochrome would be an attractive candidate for a red light sensor, and 3 phytochrome homologs are present in the Anabaena sp. 7120 genome. The Anabaena rhodopsin $\left(\lambda_{\max }=543 \mathrm{~nm}\right)$ is a candidate for the green light sensor, and may function alone to discriminate color via its photochronic reactions (Vogeley et al., 2004). The two major biliproteins in Synechocystis sp. 6830 are phycocyanin $\left(\lambda_{\max }=617 \mathrm{~nm}\right)$ and allophycocyanin $\left(\lambda_{\max }=650 \mathrm{~nm}\right)$ (Toole et al., 1998). Interestingly, the phycoerythrin gene which is regulated by green light is missing in the genome of Synechocystis which does not contain an opsin-encoding gene.

\subsection{4}

\section{Other Bacterial Rhodopsins}

\subsubsection{Magnetospirillum}

Genome sequencing of the $\alpha$-proteobacterium Magnetospirillum magnetotacticum revealed a microbial opsin gene (Table 1), proceeded by a homolog of brp, which encodes an enzyme for synthesis of retinal from $\beta$-carotene in $H$. salinarum (Peck et al., 2001). The two gene-operon contains a single promoter.

\subsubsection{Gloeobacter violaceus PCC 7421}

Gloeobacter is a unicellular cyanobacterium and the complete genome of this strain has been sequenced (Nakamura et al., 2003). There is only one type 1 rhodopsin gene, which unlike that of Anabaena, encodes a carboxylate (Glu) at the BR D96 position, suggesting a proton-pumping function.

Figure 1.3 Functional diversity among microbial rhodopsins. Domains of the two sensory rhodopsins from Chlamydomonas reinhardtii, CSRA and CSRB, based on secondary structure predictions, compared with those for proteorhodopsin, halorhodopsin and sensory rhodopsin I (in a dimeric complex with its cognate dimeric transducer) from haloarchaea and cyanobacterial sensory rhodopsin from Anabaena. The retinal chromophore (shown in red) is covalently linked to a conserved lysine residue in the seventh transmembrane helix in each protein. Colors shown are approximately the color of the pigments. Residues in helix $\mathrm{C}$ of prote- orhodopsin that are important for proton translocation, Asp-97 and Glu-108, and the amino acid differences at their corresponding positions in the other rhodopsins are highlighted. The corresponding residues are not shown for halorhodopsin (see text) to avoid the impression that they are on the chloride translocation path. Transducer domains or proteins shown in green are presumably involved in the post-receptor signal transduction processes. For the cytoplasmic $14-\mathrm{kDa}$ protein associated with ASR and for CSRA and CSRB, the numbers indicated correspond to the number of amino acid residues in each module. 
1.5

\section{Eukaryotic Microbial Rhodopsins}

\subsection{1}

\section{Fungal Rhodopsins}

A genome sequencing project on the filamentous fungus Neurospora crassa revealed the first of the eukaryotic homologs, designated NOP-1 (Bieszke et al., 1999a), and search of genome databases currently in progress indicates the presence of archaeal rhodopsin homologs in various fungi including plant and human pathogens - Ascomycetes: Botrytis cinerea, Botryotinia fuckeliana (anamorph Botrytis cinerea), Fusarium sporotrichioides, Gibberella zeae (anamorph Fusarium graminearum), Leptosphaeria maculans, Mycosphaerella graminicola (two opsin homologs) and Basidiomycetes: Cryptococcus neoformans and Ustilago maydis. Each of these organisms contains genes predicted to encode proteins with the retinal-binding lysine in the seventh helix and high identity in the retinal-binding pocket. The Asp Schiff base counter ion and proton acceptor (Asp85 in BR) is conserved among all fungal opsin homologs and the carboxylate proton donor specific to proton pumps (Asp96 in BR) is also either Asp or Glu except in Cryptococcus which contains an Ala residue.

The nop-1 gene was heterologously expressed in the yeast Pichia pastoris, and it encodes a membrane protein that forms with all-trans retinal a green light-absorbing pigment $\left(\lambda_{\max }=534 \mathrm{~nm}\right)$ with a spectral shape and bandwidth typical of rhodopsins (Bieszke et al., 1999b). Laser-flash kinetic spectroscopy of the retinal-reconstituted NOP-1 pigment (i.e. Neurospora rhodopsin) in Pichia membranes reveals that it undergoes a seconds-long photocycle with long-lived intermediates spectrally similar to intermediates detected in BR and other members of the type 1 family.

The physiological function of Neurospora rhodopsin has not yet been identified. Based on the long lifetime of the intermediates in its photocycle and its apparent lack of ion-transport activities [at least when heterologously expressed (Brown et al., 2001)], it seems likely to serve as a sensory receptor for one or more of the several different light responses exhibited by the organism, such as photocarotenogenesis or light-enhanced conidiation. Neurospora is non-motile, but phototaxis by zoospores of the motile fungus Allomyces reticulatus has been shown to be retinal-dependent (Saranak and Foster, 1997) and therefore photomotility modulation is a likely photosensory function of rhodopsins in this particular fungal species.

A blue-green light-induced photocycle in Cryptococcus neoformans native membranes has been detected and confirmed as deriving from the rhodopsin pigment by its absence in an opsin gene-deletion mutant. The photocycle is typical of a microbial rhodopsin exhibiting a blue-shifted intermediate characteristic of a deprotonated Schiff base species and a 100-150 ms half-life (pH 7.0, 25 ${ }^{\circ} \mathrm{C}$ ) (authors, unpublished). 


\section{Algal Rhodopsins}

The rhodopsins of the green alga Chlamydomonas reinhardtii are the only ones in eukaryotic microbes to have an identified physiological function, namely photoreception controlling motility behavior (Sineshchekov et al., 2002). Two type 1 opsin genes were identified in the $C$. reinhardtii genome. A microbial rhodopsin homolog gene is also present in Guillardia theta, which is a small biflagellate organism considered both a protozoan and an alga, and opsin genes are also found in the dinoflagellate $P Y$ rocystis lunula and Acetabularia acetabulum which is a unicellular green alga of the order Dasycladales found in warm waters of sheltered lagoons. The CSOA Q CSOB (Chlamydomonas sensory opsin A and B) genes encode 712 and 737 amino acid proteins (Figure 1.1). The N-terminal 300 residues have a significant homology to archaeal rhodopsins with seven transmembrane helices and the conserved retinal binding pocket (Figure 1.1). The Chlamydomonas rhodopsins provide the first examples of evolution fusing the microbial rhodopsin motif with other domains.

Early work established that Chlamydomonas uses retinylidene receptors for photomotility responses. Restoration of photomotility responses by retinal addition to a pigment-deficient mutant of $C$. reinhardtii first indicated a retinal-containing photoreceptor (Foster et al., 1984). Subsequent in vivo reconstitution studies with retinal analogs prevented from isomerizing around specific bonds ("isomer-locked retinals") in several laboratories further established that the Chlamydomonas rhodopsins governing phototaxis and the photophobic response have the same isomeric configuration (all-trans), photoisomerization across the C13-C14 double bond (all-trans to 13-cis), and 6-s-trans ring-chain conformation (co-planar) as the archaeal rhodopsins (Hegemann et al., 1991; Lawson et al., 1991; Sakamoto et al., 1998; Sineshchekov et al., 1994; Takahashi et al., 1991).

The proteins encoded by $c s o \mathrm{~A}$ and $c s o \mathrm{~B}$ complexed with retinal (called CSRA and CSRB) are the first of the eukaryotic archaeal-type rhodopsins for which we can assign physiological roles (Sineshchekov et al., 2002). RNA $i$ suppression of the genes established that CSRA and CSRB mediate both phototaxis (Sineshchekov et al., 2002) and photophobic reactions (Govorunova et al., 2004) to high- and low-intensity light, respectively. The functions of the two rhodopsins were demonstrated by analysis of electrical currents and motility responses in transformants with RNA $i$ directed against each of rhodopsin genes. CSRA has an absorption maximum near $510 \mathrm{~nm}$ and mediates a fast photoreceptor current that saturates at high light intensity. In contrast, CSRB absorbs maximally at $470 \mathrm{~nm}$ and generates a slow current saturating at low light intensity (Sineshchekov et al., 2002). The rhodopsin domains of CSRA (Nagel et al., 2002) and CSRB (Nagel et al., 2003) have been shown to exhibit light-induced proton-channel activity in Xenopus oocytes. The relationship of this activity to their control of motility-regulating currents in C. reinhardtii is not clear. A more detailed review of the sensory rhodopsins in this organism, including 3 additional genome-predicted sensory rhodopsins, CSRC, CSRD, and CSRE, called also cop5, 6, and 7 (Kateriya et al., 2004), appears in this volume (Sineshchekov and Spudich, Chapter 2). 
To clarify a possibly confusing series of reports in the literature, we mention here a protein that binds radiolabeled retinal, and named on this basis "chlamyrhodopsin," that had been isolated from Chlamydomonas eyespot preparations (Deininger et al., 1995). For several years this most abundant protein in the eyespot membranes was assumed and often cited by the authors of that work as the photoreceptor for photomotile responses. However, its gene-predicted primary sequence, as well as that of a similar Volvox protein (Ebnet et al., 1999), suggest 2-4 transmembrane helices and no homology to archaeal opsins, nor is a photoactive retinal binding site evident from the sequences. Moreover, recently the "chlamyrhodopsin" has been ruled out as the photoreceptor pigment for either phototaxis or photophobic responses in C. reinhardtii (Fuhrmann et al., 2001).

\section{6}

\section{Spectral Tuning}

Comparison of the primary sequence (Figure 1.1) alone gives hints to distinguishing properties of different microbial rhodopsins, but most properties cannot be deduced from primary structure alone. The Leu/Gln spectral-tuning switch at position 105 in GPR and BPR discussed above was revealed through structural modeling and mutagenesis. However, we were fortunate that a relatively simple single-residue switch is responsible for most of the color difference in that case, and, more generally, detailed knowledge of atomic structure will probably be required to elucidate spectral tuning mechanisms of most microbial rhodopsins. An exemplary case is that of NpSRII (from Natronomonas pharaonis) which is unusual in that its maximal absorption is shifted 70-90 $\mathrm{nm}$ to the blue of the other archaeal pigments (Tomioka and Sasabe, 1995). Mutagenic substitution of 10 residues, in or near the retinal-binding pocket with their corresponding BR residues, produced only a 28-nm red shift of the NpSRII absorption maximum (Kamo et al., 2001; Shimono et al., 2000). Structural differences responsible for the shift are evident in the 2.4-Angstrom resolution structure (Luecke et al., 2001). One notable change is a displacement of the guanidinium group of $\mathrm{Arg}^{72}$ by $1.1 \AA$ coupled with a rotation away from the Schiff base in NpSRII. This increase in distance reduces the influence of $\mathrm{Arg}^{72}$ on the counterion, thus strengthening the Schiff base/counterion interaction, shifting the absorption to shorter wavelengths. In addition the position of the positive charge destabilizes the excited state contributing further blue shift (Ren et al., 2001). $\mathrm{Arg}^{72}$ is repositioned as a consequence of several factors, including movement of its helix backbone by $0.9 \AA$ and the cavity created by changes from BR: Phe ${ }^{208} \rightarrow \mathrm{Ile}^{197}, \mathrm{Glu}^{194} \rightarrow \mathrm{Pro}^{183}$, and $\mathrm{Glu}^{204} \rightarrow \mathrm{Asp}^{192}$. Hence the spectral tuning results from precise positioning of retinal binding-pocket residues and the guanidinium of $\mathrm{Arg}^{72}$, which could not be deduced from primary structure, but required atomic resolution tertiary structure information. 


\section{7}

\section{A Unified Mechanism for Molecular Function?}

The idea that in microbial rhodopsins the sensory signaling mechanisms result from evolution "tweaking" the transport mechanism was suggested by the observation that SRI carries out light-driven proton pumping, but only when it is free of its transducer (Bogomolni et al., 1994; Olson and Spudich, 1993; Spudich and Spudich, 1993; Spudich, 1994). The HtrI protein was found to close or prevent the opening of a cytoplasmic proton-conducting channel in SRI during its photocycle. This finding led to the notion that a chemotaxis receptor progenitor of HtrI evolved an interaction with a proton-transporter progenitor of SRI, coupling to its pumping mechanism and thereby blocking the pump and converting the transport rhodopsin to a sensory receptor. NpSRII was also observed under some conditions to exhibit light-driven proton transport which was also prevented by its interaction with its transducer, HtrII (Schmies et al., 2001; Sudo et al., 2001).

That the transducer-inhibition of light-driven transport occurs in both haloarchaeal rhodopsins further supports that the interaction blocking the transport is a critical aspect of the signaling mechanism. A tilting of helices, primarily helix F, contributes to opening a cytoplasmic channel in the latter half of the photocycle in BR (Subramaniam and Henderson, 2000). A unifying mechanism is that ion transport and sensory signaling use the same retinal-driven protein structural changes, which is the conformational change that opens the cytoplasmic channel in the proton transport cycle. The key feature of the model is that consequences of retinal photoisomerization, including light-induced disruption of the salt bridge between the protonated Schiff base on helix G and aspartyl counterion on helix C (Spudich et al., 1997), triggers tilting of helix $\mathrm{F}$ to which the Htr transmembrane helices are coupled. Supporting this mechanism are (i) the proton-pumping by the sensory rhodopsins, (ii) its inhibition by transducer interaction discussed above, and (iii) light-induced tilting of helix F in N. pharaonis SRII, concluded from site-directed spin-labeling measurements (Wegener et al., 2000). Furthermore, (iv) genetic evidence supports helix-F involvement in signaling (Jung and Spudich, 1998).In addition, (v) substitution of the Schiff base counterion Asp85 with asparagine induces helix-F tilting in the dark in BR and the corresponding substitution in H. salinarum SRII partially activates the receptor in the dark (Spudich et al., 1997). Finally (vi), helix F interacts with the two transmembrane helices of the HtrII fragment co-crystallized with NpSRII (Gordeliy et al., 2002).

Another prediction is that, since in the model SR helix tilting is transmitted to the Htr protein by direct helix-helix contacts, alterations in structure must occur in the Htr transmembrane domains between the receptor interaction sites and the cytoplasmic domain of the transducer, where the activity of the bound histidine kinase is controlled. Such structural alterations have been detected as light-induced changes in interactions between spin labels introduced into the NpHtrII transmembrane helices (Wegener et al., 2000) and changes of disulfide bond formation rates between engineered cysteines (Yang and Spudich, 2001). In both studies the data indicate that the second transmembrane segment (TM2) of NpHtrII is more conformationally active 
than TM1. The authors of the site-directed spin-labeling study further suggest a signal-transfer mechanism in which TM2 undergoes a rotary motion in response to the helix F tilt in the photoactivated receptor (Wegener et al., 2000), and interaction of the receptor's E-F loop with the membrane proximal domain of the transducer has been implicated in signal transfer (Chen and Spudich 2004; Yang et al., 2004).

In summary, the evidence is compelling that the conformational changes in transport and sensory rhodopsins in haloarchaea share essential features despite their differing functions. For study of the newfound microbial rhodopsins, an important question is whether the light-induced conformational change observed in BR and strongly implicated in the haloarchaeal sensory rhodopsin photocycles is a key conserved feature of their functional mechanisms.

\section{8}

\section{Opsin-related Proteins without the Retinal-binding Site}

Several other genes in the fungi N. crassa (YRO2), Aspergillus nidulans, Saccharomyces cerevisiae, Schizosaccharomyces pombe, Coccidioides immitis, Coriolus versicolor, and in the plant Sorghum bicolor (sorghum) encode proteins that exhibit significant homology to type 1 rhodopsins, but are missing the critical lysine residue in the 7th helix that forms the covalent linkage with retinal. The microbial-opsin-related proteins are therefore not likely to form photoactive pigments with retinal. The most conserved region in these proteins is along helix $\mathrm{C}$, E, and the middle of helix F. It is intriguing that one of the yeast opsin-related proteins, HSP30 (heat shock protein 30), is implicated as interacting with a proton transport protein, the $\mathrm{H}^{+}$ATPase. HSP30 downregulates stress stimulation of $\mathrm{H}^{+}$ATPase activity under heat shock conditions (Piper et al., 1997; Zhai et al., 2001). It may be that the conformational switching properties of the archaeal rhodopsins have been preserved in these opsin-related proteins, while the photoactive site has been lost and its function replaced by another input module such as a protein-protein interaction domain. It is striking that opsin-related proteins lacking the retinal-binding lysine have been observed so far only in fungi and not in any of the many other classes of organisms containing type 1 rhodopsins.

\section{9}

\section{Perspective}

Type 1 rhodopsins are present in all three domains of life, and therefore progenitors of these proteins may have existed in early evolution before the divergence of archaea, eubacteria, and eukaryotes. If so, light-driven ion transport as a means of obtaining cellular energy may well have predated the development of photosynthesis, and represent one of the earliest means by which organisms tapped solar radiation as an energy source. As more rhodopsins are identified, their evolution and dissemination into such a wide variety of organisms, whether by divergence from a common progenitor or horizontal gene transfer, should become clearer. 
There is a much work to be done to understand the physiological roles and molecular mechanisms of the rhodopsins so far identified in the various microbial species. It seems likely that we will see even more members of this family as genomic sequencing becomes ever more rapid. The vast majority of microbial species have never been cultivated in a laboratory. Therefore the use of microbial rhodopsin probes in environmental genomics, which expands the search for homologous genes to uncultivated organisms, is likely to be especially fruitful.

\section{Acknowledgements}

We thank Elena Spudich for stimulating discussions. The work by the authors referred to in this review was supported by grants from the National Institutes of Health, National Science Foundation, Human Frontiers Science Program, and the Robert A. Welch Foundation.

\section{References}

Béjà, O., Aravind, L., Koonin, E.V., Suzuki, M.T., Hadd, A., Nguyen, L.P., Jovanovich, S.B., Gates, C.M., Feldman, R.A., Spudich, J.L., Spudich, E.N., and DeLong, E.F. (2000) Science 289, 1902-1906.

Béjà, O., Spudich, E.N., Spudich, J.L., Leclerc, M., and DeLong, E.F. (2001) Nature 411, 786-789.

Bieszke, J.A., Braun, E.L., Bean, L.E., Kang, S., Natvig, D.O., and Borkovich, K.A. (1999a) Proc Natl Acad Sci USA 96, 8034-8039.

Bieszke, J.A., Spudich, E.N., Scott, K.L., Borkovich, K.A., and Spudich, J.L. (1999b) Biochemistry 38, 14138-14145.

Birge, R.R. (1990) Annu Rev Phys Chem 41, 683-733.

Bogomolni, R.A., and Spudich, J.L. (1982) Proc Natl Acad Sci USA 79, 6250-6254.

Bogomolni, R.A., Stoeckenius, W., Szundi, I., Perozo, E., Olson, K.D., and Spudich, J.L. (1994) Proc Natl Acad Sci USA 91, 1018810192.

Brown, L.S., Dioumaev, A.K., Lanyi, J.K., Spudich, E.N., and Spudich, J.L. (2001) J Biol Chem 276, 32495-32505.

Chen, X. and Spudich, J.L. (2004) J Biol Chem 279, 42964-42969.

de la Torre, J.R., Christianson, L.M., Beja, O., Suzuki, M.T., Karl, D.M., Heidelberg, J., and DeLong, E.F. (2003) Proc Natl Acad Sci USA 100, 12830-12835.
Deininger, W., Kroger, P., Hegemann, U., Lottspeich, F., and Hegemann, P. (1995) EMBO J 14, 5849-5858.

Dioumaev, A.K., Brown, L.S., Shih, J., Spudich, E.N., Spudich, J.L., and Lanyi, J.K. (2002) Biochemistry 41, 5348-5358.

Dioumaev, A.K., Wang, J.M., Balint, Z., Varo, G., and Lanyi, J.K. (2003) Biochemistry 42, 6582-6587.

Ebnet, E., Fischer, M., Deininger, W., and Hegemann, P. (1999) Plant Cell 11, 14731484.

Essen, L., Siegert, R., Lehmann, W.D., and Oesterhelt, D. (1998) Proc Natl Acad Sci USA 95, 11673-11678.

Foster, K.W., Saranak, J., Patel, N., Zarilli, G., Okabe, M., Kline, T., and Nakanishi, K. (1984) Nature 311, 756-759.

Friedrich, T., Geibel, S., Kalmbach, R., Chizhov, I., Ataka, K., Heberle, J., Engelhard, M., and Bamberg, E. (2002) J Mol Biol 321, 821-838.

Fuhrmann, M., Stahlberg, A., Govorunova, E., Rank, S., and Hegemann, P. (2001) J Cell Sci 114, 3857-3863.

Gordeliy, V.I., Labahn, J., Moukhametzianov, R., Efremov, R., Granzin, J., Schlesinger, R., Buldt, G., Savopol, T., Scheidig, A.J., Klare, J.P., and Engelhard, M. (2002) Nature 419, 484-487. 
Govorunova, E.G., Jung, K.H., Sineshchekov, O.A., and Spudich, J.L. (2004) Biophys J 86, 2342-2349.

Grigorieff, N., Ceska, T.A., Downing, K.H., Baldwin, J.M., and Henderson, R. (1996) J Mol Biol 259, 393-421.

Grossman, A.R., Bhaya, D., and He, Q. (2001) J Biol Chem 276, 11449-11452.

Hegemann, P., Gartner, W., and Uhl, R. (1991) Biophys J 60, 1477-1489.

Hoff, W.D., Jung, K.H., and Spudich, J.L. (1997) Annu Rev Biophys Biomol Struct 26, 223-258.

Jerlov, N.G. (1976) in Marin Optics. Amsterdam, Oxford, New York, Elsevier.

Jung, K.H. and Spudich, J.L. (1998) J. Bacteriology 180, 2033-2042.

Jung, K.H., Spudich, E.N., Trivedi, V.D., and Spudich, J.L. (2001) J Bacteriology 183, 63656371.

Jung, K.H., Trivedi, V.D., and Spudich, J.L. (2003) Mol Microbiol 47, 1513-1522.

Kamo, N., Shimono, K., Iwamoto, M., and Sudo, Y. (2001) Biochemistry (Mosc) 66, 12771282.

Kateriya, S., Nagel, G., Bamberg, E., and Hegemann, P. (2004) News Physiol. Sci. 19, 133-137.

Kehoe, D.M., and Grossman, A.R. (1994) Semin Cell Biol 5, 303-313.

Kolbe, M., Besir, H., Essen, L.O., and Oesterhelt, D. (2000) Science 288, 1390-1396.

Krebs, R.A., Alexiev, U., Partha, R., DeVita, A.M., and Braiman, M.S. (2002) BMC Physiol 2, 5 .

Kunji, E.R., Spudich, E.N., Grisshammer, R., Henderson, R., and Spudich, J.L. (2001) J Mol Biol 308, 279-293.

Lakatos, M., Lanyi, J.K., Szakacs, J., and Varo, G. (2003) Biophys J 84, 3252-3256.

Lanyi, J.K., and Luecke, H. (2001) Curr Opin Struct Biol 11, 415-419.

Lawson, M.A., Zacks, D.N., Derguini, F., Nakanishi, K., and Spudich, J.L. (1991) Biophys J 60, 1490-1498.

Luecke, H., Schobert, B., Richter, H.T., Cartailler, J.P., and Lanyi, J.K. (1999) J Mol Biol 291, 899-911.

Luecke, H., Schobert, B., Lanyi, J.K., Spudich, E.N., and Spudich, J.L. (2001) Science 293, 1499-1503.

Man, D., Wang, W., Sabehi, G., Aravind, L., Post, A.F., Massana, R., Spudich, E.N., Spu- dich, J.L., and Béjà, O. (2003) EMBO J 22, 1725-1731.

Man-Aharonovich, D., Sabehi, G., Sineshchekov, O.A., Spudich, E.N., Spudich, J.L., and Béjà, O. (2004) Photochem Photobiol Sci 3, 459-462.

Matsuno-Yagi, A., and Mukohata, Y. (1977) Biochem Biophys Res Commun 78, 237-243.

Mullineaux, C.W. (2001) Mol Microbiol 41, 965971.

Nagel, G., Ollig, D., Fuhrmann, M., Kateriya, S., Musti, A.M., Bamberg, E., and Hegemann, P. (2002) Science 296, 2395-2398.

Nagel, G., Szellas, T., Huhn, W., Kateriya, S., Adeishvili, N., Berthold, P., Ollig, D., Hegemann, P., and Bamberg, E. (2003) Proc Natl Acad Sci USA 100, 13940-13945.

Nakamura, Y., Kaneko, T., Sato, S., Mimuro, M., Miyashita, H., Tsuchiya, T., Sasamoto, S., Watanabe, A., Kawashima, K., Kishida, Y., Kiyokawa, C., Kohara, M., Matsumoto, M. Matsuno, A., Nakazaki, N., Shimpo, S., Takeuchi, C., Yamada, M., and Tabata, S. (2003) DNA Res 10, 137-145.

Oesterhelt, D., and Stoeckenius, W. (1973) Functions of a new photoreceptor membrane. Proc Natl Acad Sci USA 70, 28532857.

Oesterhelt, D. (1998) Curr Opin Struct Biol 8, 489-500.

Olson, K.D., and Spudich, J.L. (1993) Biophys J 65, 2578-2585.

Ottolenghi, M., and Sheves, M. (1989) J Membr Biol 112, 193-212.

Palczewski, K., Kumasaka, T., Hori, T., Behnke, C.A., Motoshima, H., Fox, B.A., Le Trong, I., Teller, D.C., Okada, T., Stenkamp, R.E., Yamamoto, M., and Miyano, M. (2000) Science 289, 739-745.

Peck, R.F., Echavarri-Erasun, C., Johnson, E.A., Ng, W.V., Kennedy, S.P., Hood, L., DasSarma, S., and Krebs, M.P. (2001) J Biol Chem 276, 5739-5744.

Piper, P.W., Ortiz-Calderon, C., Holyoak, C., Coote, P., and Cole, M. (1997) Cell Stress Chaperones 2, 12-24.

Ren, L., Martin, C.H., Wise, K.J., Gillespie, N.B., Luecke, H., Lanyi, J.K., Spudich, J.L., and Birge, R.R. (2001) Biochemistry 40, 13906-13914.

Sabehi, G., Massana, R., Bielawski, J.P., Rosenberg, M., Delong, E.F., and Beja, O. (2003) Environ Microbiol 5, 842-849. 
Sakamoto, M., Wada, A., Akai, A., Ito, M., Goshima, T., and Takahashi, T. (1998) FEBS Lett 434, 335-338.

Saranak, J., and Foster, K.W. (1997) Nature 387, 465-466.

Schmies, G., Engelhard, M., Wood, P.G., Nagel, G., and Bamberg, E. (2001) Proc Natl Acad Sci USA 98, 1555-1559.

Schobert, B., and Lanyi, J.K. (1982) J Biol Chem 257, 10306-10313.

Shimono, K., Iwamoto, M., Sumi, M., and Kamo, N. (2000) Photochem Photobiol 72, 141-145.

Sineshchekov, O.A., Govorunova, E.G., Der, A., Keszthelyi, L., and Nultsch, W. (1994) Biophys J 66, 2073-2084.

Sineshchekov, O.A., Jung, K.H., and Spudich, J.L. (2002) Proc Natl Acad Sci USA 99, 86898694.

Spudich, E.N., and Spudich, J.L. (1993) J Biol Chem 268, 16095-16097.

Spudich, E.N., Zhang, W., Alam, M., and Spudich, J.L. (1997) Proc Natl Acad Sci U S A 94, 4960-4965.

Spudich, J.L., and Bogomolni, R.A. (1984) Nature 312, 509-513.

Spudich, J.L. (1994) Cell 79, 747-750.

Spudich, J.L., Zacks, D.N., and Bogomolni, R.A. (1995) Isr J Photochem 35, 495-513.

Spudich, J.L., Yang, C.S., Jung, K.H., and Spudich, E.N. (2000) Annu Rev Cell Dev Biol 16, 365-392.

Spudich, J.L. (2002) Nature Struct. Biol 9, 797-799.

Subramaniam, S., and Henderson, R. (2000) Nature 406, 653-657.

Sudo, Y., Iwamoto, M., Shimono, K., and Kamo, N. (2001) Photochem Photobiol 74, 489-494.

Takahashi, T., Tomioka, H., Kamo, N., and Kobatake, Y. (1985) FEMS Microbiol Lett 28, 161-164.

Takahashi, T., Yan, B., Mazur, P., Derguini, F., Nakanishi, K., and Spudich, J.L. (1990) Biochemistry 29, 8467-8474.
Takahashi, T., Yoshihara, K., Watanabe, M., Kubota, M., Johnson, R., Derguini, F., and Nakanishi, K. (1991) Biochem Biophys Res Commun 178, 1273-1279.

Tomioka, H., and Sasabe, H. (1995) Biochim Biophys Acta 1234, 261-267.

Toole, C.M., Plank, T.L., Grossman, A.R., and Anderson, L.K. (1998) Mol Microbiol 30, 475486.

Varo, G. (2000) Biochim Biophys Acta 1460, 220-229.

Venter, J.C., Remington, K., Heidelberg, J.F., Halpern, A.L., Rusch, D., Eisen, J.A., Wu, D., Paulsen, I., Nelson, K.E., Nelson, W., Fouts, D.E., Levy, S., Knap, A.H., Lomas, M.W., Nealson, K., White, O., Peterson, J., Hoffman, J., Parsons, R., Barden-Tillson, H., Pfannkoch, C., Rogers, Y.H., and Smith, H.O. (2004) Science 306, 66-74.

Vogeley, L., Sineshchekov, O.A., Trivedi, V.D., Sasaki, J., Spudich, J.L. and Luecke, H. (2004) Anabaena Sensory Rhodopsin: A Photochromic Color Sensor at $2.0 \AA$. Science 306, 1390-1393.

Wang, W.W., Sineshchekov, O.A., Spudich, E.N., and Spudich, J.L. (2003) J Biol Chem 278, 33985-33991.

Wegener, A.A., Chizhov, I., Engelhard, M., and Steinhoff, H.J. (2000) J Mol Biol 301, 881891.

Yan, B., Spudich, J.L., Mazur, P., Vunnam, S., Derguini, F., and Nakanishi, K. (1995) J Biol Chem 270, 29668-29670.

Yang, C.S., and Spudich, J.L. (2001) Biochemistry 40, 14207-14214.

Yang, C.S., Sineshchekov, O.A., Spudich, E.N. and Spudich, J.L. (2004) J Biol Chem 279: 42970-42976.

Zhai, Y., Heijne, W.H., Smith, D.W., and Saier, M.H., Jr. (2001) Biochim Biophys Acta 1511, 206-223.

Zhang, X.N., Zhu, J., and Spudich, J.L. (1999) Proc Natl Acad Sci USA 96, 857-862. 
